Supporting Information for:

\title{
Estimated Long-term (1981-2016) Concentrations of Ambient Fine Particulate Matter across North America from Chemical Transport Modeling, Satellite Remote Sensing and Ground-based Measurements
}

Jun Meng ${ }^{1 *}$, Chi Li ${ }^{1}$, Randall V. Martin ${ }^{1,2}$, Aaron van Donkelaar ${ }^{1}$, Perry Hystad ${ }^{3}$, Michael Brauer ${ }^{4}$

\begin{abstract}
Affiliations
${ }^{1}$ Department of Physics and Atmospheric Science, Dalhousie University, Halifax, Nova Scotia, B3H 4R2,

Canada

${ }^{2}$ Smithsonian Astrophysical Observatory, Harvard-Smithsonian Center for Astrophysics, Cambridge, MA 02138, USA

${ }^{3}$ College of Public Health and Human Sciences, Oregon State University, Corvallis, OR 97331, USA

${ }^{4}$ School of Population and Public Health, The University of British Columbia, 2206 East Mall, Vancouver, British Columbia, V6T 1Z3, Canada
\end{abstract}

*Correspondence to Jun Meng (Jun.Meng@Dal.ca)

Supplemental contains: 17 pages, 5 Descriptions, 5 Tables, 10 Figures 


\section{Contents}

SI.1 DESCRIPTION OF PREDICTION OF HISTORICAL PM 2.5 FROM MEASURED PM 10 AND TSP................................S3

SI.2 Description of Estimated PM 2.5 Data Without Satellite Remote Sensing Information........................S5

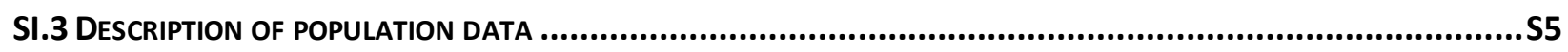

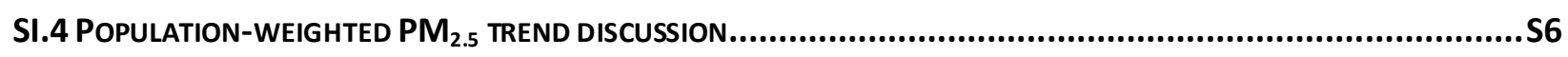

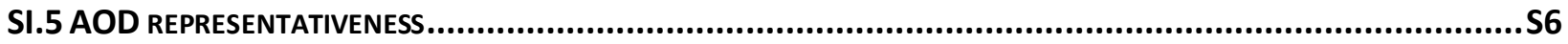

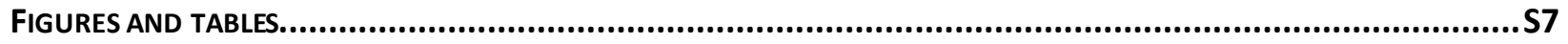

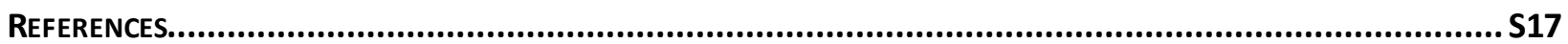




\section{SI.1 Description of prediction of Historical $\mathrm{PM}_{2.5}$ from Measured $\mathrm{PM}_{10}$ and TSP}

We collect ground-based measurements over Canada and the United States. All Canadian particulate matter (PM) data were downloaded from the National Air Pollutant Surveillance (NAPS) website (http://maps-cartes.ec.gc.ca/rnspa-naps/data.aspx?lang=en). Data included all continuous PM measurement data, dichotomous sampler data and total suspended particulate (TSP) data. Continuous $\mathrm{PM}_{2.5}$ was measured using a range of monitoring methods and there are known biases with certain methods, which were corrected using the equations in Table S2 (provided by NAPS). Once data were corrected the average of all continuous $\mathrm{PM}_{2.5}$ data measured at a single site (if present) was calculated to represent the monitor average. PM data for the United States were downloaded from the US Air Quality System Data Mart using the pre-generated daily data files for $\mathrm{PM}_{10}$ and $\mathrm{PM}_{2.5}$

(https://aqs.epa.gov/aqsweb/airdata/download files.html). For TSP, only annual files were available. In addition, data from the inhalable particle network (IPN) ${ }^{1}$ was included, which consisted of $\mathrm{PM}_{2.5}$ measurements in the early 1980's.

Historical estimates of monitoring $\mathrm{PM}_{2.5}$ concentrations from the $\mathrm{PM}_{10}$ and TSP measurements were created using models developed from co-located $\mathrm{PM}_{2.5}, \mathrm{PM}_{10}$ and TSP measurements. Models were developed for pre-2000 concentrations when $\mathrm{PM}_{2.5}$ measurement data were sparse. The unit of analysis was monthly concentrations for $\mathrm{PM}_{2.5}$ and $\mathrm{PM}_{10}$ models and yearly concentrations for TSP models. Separate models were created using Canada and US data to maximize use of the Canadian specific data, which would be swamped by the larger numbers of US monitoring data if pooled together. Each model included monthly $\mathrm{PM}_{10}$ or yearly TSP measurements, year, month, region (Province or State), interactions terms for $\mathrm{PM}_{10}$ or TSP 
and month and region and a random intercept for monitoring station. A random effects model is used to account for station-specific effects when multiple monitors exist at a single station.

Monthly $\mathrm{PM}_{10}$ models in Canada and the US were able to predict a large portion of measured $\mathrm{PM}_{2.5}$. In Canada, 323 stations operating prior to the year 2000 were used to build the model, representing 2,706 monitor months. The fixed effects model alone predicted $75 \%$ of the measured $\mathrm{PM}_{2.5}$ and when monitor random effects were included the model explained 95\% of measured PM2.5 (Figure S1). Table S3 summarizes the model fixed effects contributions to the model. This increase in model performance is expected as most PM stations in Canada measure both $\mathrm{PM}_{10}$ and $\mathrm{PM}_{2.5}$ using dichotomous samplers. In the United States, 3,403 stations were used to build the model, representing 10,802 monitor months. The fixed effects model predicted $62 \%$ of measured $\mathrm{PM}_{2.5}$ variations and the random effects model explained $70 \%$.

(Figure S1). Table S4 summarizes the model fixed effects.

During the 1980's there were limited $\mathrm{PM}_{10}$ measurements. We therefore included TSP to further predict annual $\mathrm{PM}_{2.5}$ concentrations. Annual models were created to predict $\mathrm{PM}_{2.5}$ due to the annual TSP data availability in the United States. In Canada, the fixed effects model predicted $82 \%$ of the measured $\mathrm{PM}_{2.5}$ annually and the RMSE improved when monitor random effects were included the model (Figure S2). In the United States, the fixed effects model predicted $76 \%$ of measured $\mathrm{PM}_{2.5}$ variations and the random effects model explained $91 \%$ (Figure S3).

The value of the random effects model reflects how many air monitor stations are used in the model building process (i.e. monitors that have both $\mathrm{PM}_{10}$ and $\mathrm{PM}_{2.5}$ monitoring data at some point) and thus have best linear unbiased prediction (BLUP) of the random effects in the 
model prediction. In Figure S1 (Canada), most monitors had some overlap between measured $\mathrm{PM}_{2.5}$ and $\mathrm{PM}_{10}$. While in the US, there were more monitors that had only $\mathrm{PM}_{10}$ measurements, which result in the random effects model not having as large of an influence on improving $\mathrm{R}^{2}$. For the TSP and $\mathrm{PM}_{2.5}$ models the opposite is true, where in Canada there are very few monitors (in total) and even less that had both TSP and $\mathrm{PM}_{2.5}$ measures. In the US there were more co-located TSP and $\mathrm{PM}_{2.5}$ monitors which leads to a better prediction with the random effects included.

\section{SI.2 Description of Estimated PM $_{2.5}$ data without Satellite Remote Sensing information}

In order to test the effect of the satellite remote sensing information on our dataset, we generated a sensitivity dataset which does not contain satellite remote sensing information. Instead of downscaling the GEOS-Chem simulation with satellite-derived $\mathrm{PM}_{2.5}$, we applied geographically weighted regression (GWR) directly to the GEOS-Chem simulation (1989-2016) following van Donkelaar et al. ${ }^{2}$ using available $\mathrm{PM}_{2.5}$ observations, and $\mathrm{PM}_{2.5}$ concentrations inferred from $\mathrm{PM}_{10}$ observation. For years 1981-1988, we used the information on inter-annual variation from ground-based measurements to back-cast the gridded $\mathrm{PM}_{2.5}$ concentrations as described in section 2.2 .

\section{SI.3 Description of population data}

We downloaded population data from the National Aeronautics and Space Administration Socioeconomic Data and Application Center (SEDAC) for the years 1980, 1990, 
2000, 2005, 2010 and 2015. Then we used linear interpolation and extrapolation to generate the population data in each year over 1980 to 2016.

\section{SI.4 Population-weighted $\mathrm{PM}_{2.5}$ trend discussion}

Figure S7 shows the time series of population-weighted average $\mathrm{PM}_{2.5}$ of this study and our most recent satellite-derived $\mathrm{PM}_{2.5}{ }^{3}$. Our estimates are consistent with our most recent work with a RMSD of $0.4 \mu \mathrm{g} / \mathrm{m}^{3}$ during $2000-2016$. The trend over $2000-2016$ of our estimate is $-0.30 \mu \mathrm{g} / \mathrm{m}^{3} / \mathrm{yr}$ (Cl 95\%: $-0.33,-0.27$ ), which is within the uncertainty of $-0.27 \mu \mathrm{g} / \mathrm{m}^{3} / \mathrm{yr}$ (Cl 95\%: $-0.30,-0.25)$ reported in van Donkelaar et al. ${ }^{3}$ Our earlier work exhibits similar trends for North America $^{4}\left(-0.30 \mu \mathrm{g} / \mathrm{m}^{3} / \mathrm{yr}(\mathrm{Cl} 95 \%\right.$ : $\left.-0.34,-0.26)\right)$ using 1998-2012. Overall, the trend of $\mathrm{PM}_{2.5}$ estimates in this study is consistent with our prior datasets during the same years.

\section{SI.5 AOD representativeness}

For insight into the representativeness of the 2004-2008 time period, Figure 88 shows the spatial distribution of AOD for the time periods 2001-2005, 2004-2008 and 2012-2016 from the MODIS MAIAC ${ }^{5,6}$ product at $1 \mathrm{~km}$ resolution. The spatial structure of the 2004-2008 dataset exhibits a high degree of consistency with the two time periods with an $R^{2}$ of 0.93 versus the 2001-2005 time period, and of 0.81 versus the 2012-2016 time period. Additional insight is offered by the spatial distribution of a recent satellite derived $\mathrm{PM}_{2.5}$ dataset $^{3}$ as shown in Figure S9. The spatial structure of the 2004-2008 dataset is highly consistent with that for the 20012005 time period $\left(R^{2}=0.97\right)$ and the 2012-2016 time period $\left(R^{2}=0.77\right)$. The change in $P M_{2.5}$ 
across these time periods exhibits a large scale reduction over the eastern United States, driven by emission controls, and a large scale increase over northern Canada, driven by fire activity.

These regional changes motivate our use of the GEOS-Chem model to represent the long-term evolution of the spatial distribution of $\mathrm{PM}_{2.5}$

Figures and tables

Table S1 Summary of available monitoring PM data for selected years during 1981 - 2016.

\begin{tabular}{l|l|rrrrrrrr}
\hline Country/Region & Type & $\mathbf{1 9 8 1}$ & $\mathbf{1 9 8 5}$ & $\mathbf{1 9 9 0}$ & $\mathbf{1 9 9 5}$ & $\mathbf{2 0 0 0}$ & $\mathbf{2 0 0 5}$ & $\mathbf{2 0 1 0}$ & $\mathbf{2 0 1 5}$ \\
\hline \multirow{2}{*}{ Canada } & $\mathrm{TSP}$ & 117 & 90 & 78 & 50 & & & & \\
\cline { 2 - 10 } & $\mathrm{PM}_{10}$ & 3 & 20 & 62 & 46 & 24 & 22 & 0 \\
\cline { 2 - 9 } & $\mathrm{PM}_{2.5}$ (dichot) & 11 & 10 & 18 & 19 & 27 & 28 & 22 \\
\cline { 2 - 9 } & $\mathrm{PM}_{2.5}$ (continuous) & & & & 1 & 50 & 158 & 90 & 94 \\
\hline \multirow{3}{*}{ United States } & $\mathrm{TSP}$ & 3253 & 2403 & 587 & 302 & 97 & 55 & 51 & 0 \\
\cline { 2 - 10 } & $\mathrm{PM}_{10}$ & & 373 & 1363 & 1664 & 761 & 595 & 451 & 349 \\
\cline { 2 - 9 } & $\mathrm{PM}_{2.5}$ & & & 44 & 68 & 1212 & 1355 & 1329 & 1330 \\
\hline
\end{tabular}

Table S2. Transformation functions for Canadian monitoring methods by region.

\begin{tabular}{l|c|c|c|c}
\hline Name & Season & Region & Slope & Intercept \\
\hline TEOM_30 & Cold & East & 1.44 & 0.47 \\
\hline TEOM_30 & Warm & East & 0.98 & 1.24 \\
\hline TEOM_30 & Cold & West & 1.36 & 1.27 \\
\hline TEOM_30 & Warm & West & 1.01 & 1.42 \\
\hline TEOM_40 & Cold & West & 1.30 & 0.94 \\
\hline TEOM_40 & Warm & West & 0.94 & 1.72 \\
\hline BAM & Cold & East & 0.88 & 0.00 \\
\hline BAM & Warm & East & 0.88 & 0.15 \\
\hline FDMS & Cold & East & 0.87 & -0.48 \\
\hline FDMS & Warm & East & 0.92 & -0.09 \\
\hline *East= Provinces Ontario and East; West= Provinces West of Ontario \\
** Cold=November-March; Warm=April-October \\
\hline
\end{tabular}


Table S3. Predicting $\mathrm{PM}_{2.5}$ from $\mathrm{PM}_{10}$ in Canada, summary of model predictors fixed effect contributions

\begin{tabular}{|c|c|c|c|c|}
\hline \multicolumn{5}{|c|}{ Type III Tests of Fixed Effects } \\
\hline Effect & Num DF ${ }^{1}$ & Den DF² & F-Value ${ }^{3}$ & $\operatorname{Pr}>F^{4}$ \\
\hline $\mathbf{P M}_{10}$ & 1 & 202 & 1188.75 & $<.0001$ \\
\hline Years prior to 2000 & 1 & 202 & 58.76 & $<.0001$ \\
\hline PM10_avg*Years prior to 2000 & 1 & 202 & 18.36 & $<.0001$ \\
\hline Month & 11 & 202 & 1.86 & 0.0458 \\
\hline PM10*Month & 11 & 202 & 10.39 & $<.0001$ \\
\hline Region & 4 & 202 & 11.12 & $<.0001$ \\
\hline $\mathrm{PM}_{10} *$ Region & 4 & 202 & 90.97 & $<.0001$ \\
\hline Years prior to $2000 *$ Region & 4 & 202 & 3.00 & 0.0195 \\
\hline \multicolumn{5}{|l|}{$\begin{array}{l}{ }^{1} \text { Numerator degrees of freedom } \\
{ }^{2} \text { Denominator degrees of freedom }\end{array}$} \\
\hline
\end{tabular}

Table S4. Predicting $\mathrm{PM}_{2.5}$ from $\mathrm{PM}_{10}$ in the United States, summary of model predictors fixed effect contributions

\begin{tabular}{|c|c|c|c|c|}
\hline \multicolumn{5}{|c|}{ Type III Tests of Fixed Effects } \\
\hline Effect & Num DF ${ }^{1}$ & Den $\mathrm{DF}^{2}$ & F-Value ${ }^{3}$ & $\operatorname{Pr}>F^{4}$ \\
\hline$P_{10}$ & 1 & 10160 & 1290.16 & $<.0001$ \\
\hline Years prior to 2000 & 1 & 10160 & 23.05 & $<.0001$ \\
\hline State & 50 & 10160 & 7.85 & $<.0001$ \\
\hline $\mathrm{PM}_{10} *$ State & 50 & 10160 & 17.19 & $<.0001$ \\
\hline Month & 11 & 10160 & 13.35 & $<.0001$ \\
\hline PM10*Month & 11 & 10160 & 60.51 & $<.0001$ \\
\hline \multicolumn{5}{|c|}{$\begin{array}{l}{ }^{1} \text { Numerator degrees of freedom } \\
{ }^{2} \text { Denominator degrees of freedom }\end{array}$} \\
\hline
\end{tabular}

Table S5. Statistics of back-casted $\mathrm{PM}_{2.5}$ against estimated $\mathrm{PM}_{2.5}$ in years 2001-2008

\begin{tabular}{l|llllllll}
\hline & 2001 & 2002 & 2003 & 2004 & 2005 & 2006 & 2007 & 2008 \\
\hline$R^{2}$ & 0.94 & 0.92 & 0.93 & 0.81 & 0.87 & 0.82 & 0.86 & 0.85 \\
$\operatorname{RMSE}\left(\mu \mathrm{g} / \mathrm{m}^{3}\right)$ & 0.82 & 0.84 & 0.83 & 1.3 & 1.2 & 1.4 & 1.3 & 1.1 \\
\hline
\end{tabular}



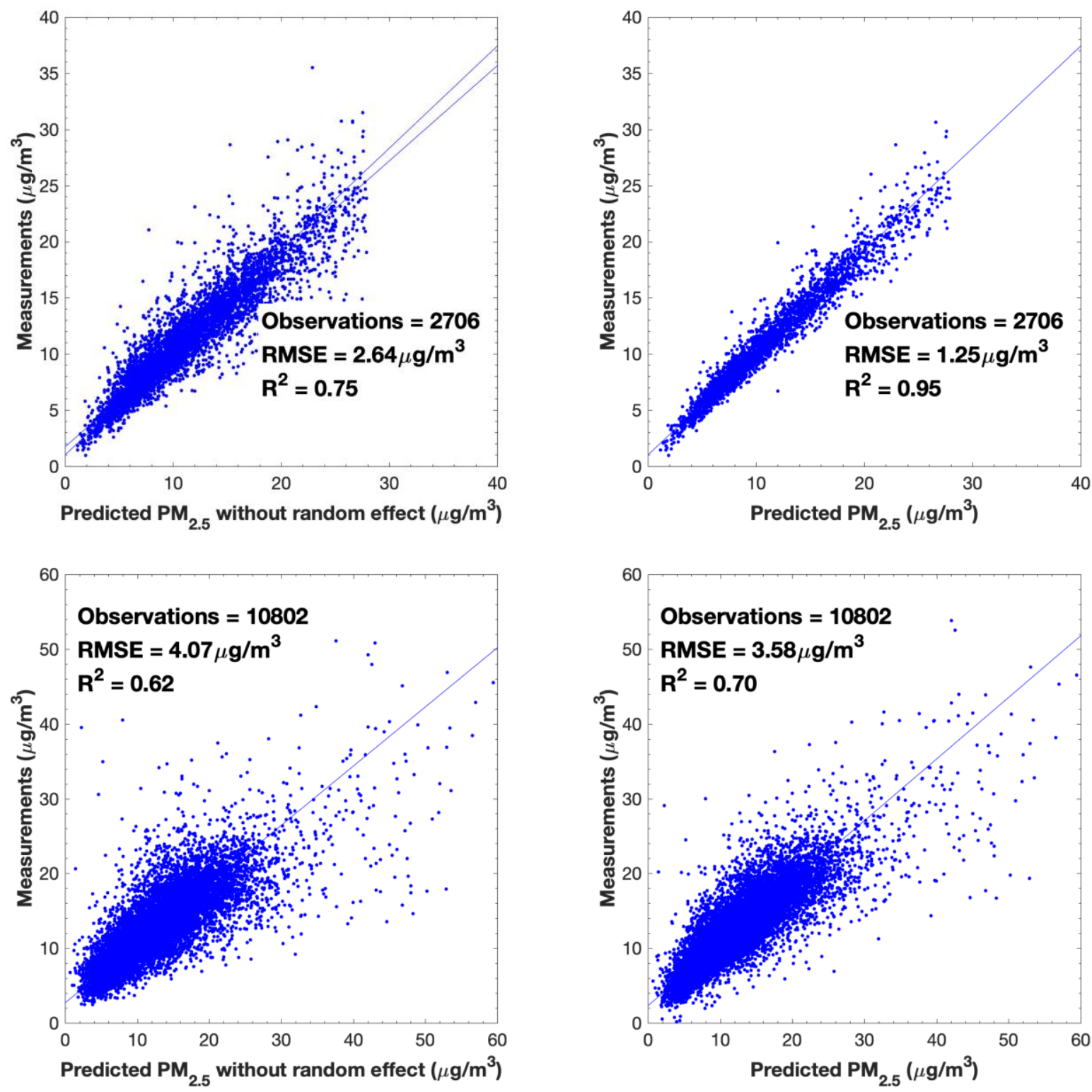

Figure S1. Predictive models of monthly PM 2.5 from co-located PM10 measurements in Canada (top panels) and the United States (bottom panels). The left panels are models without random effects and the right panels are models with random effects. 

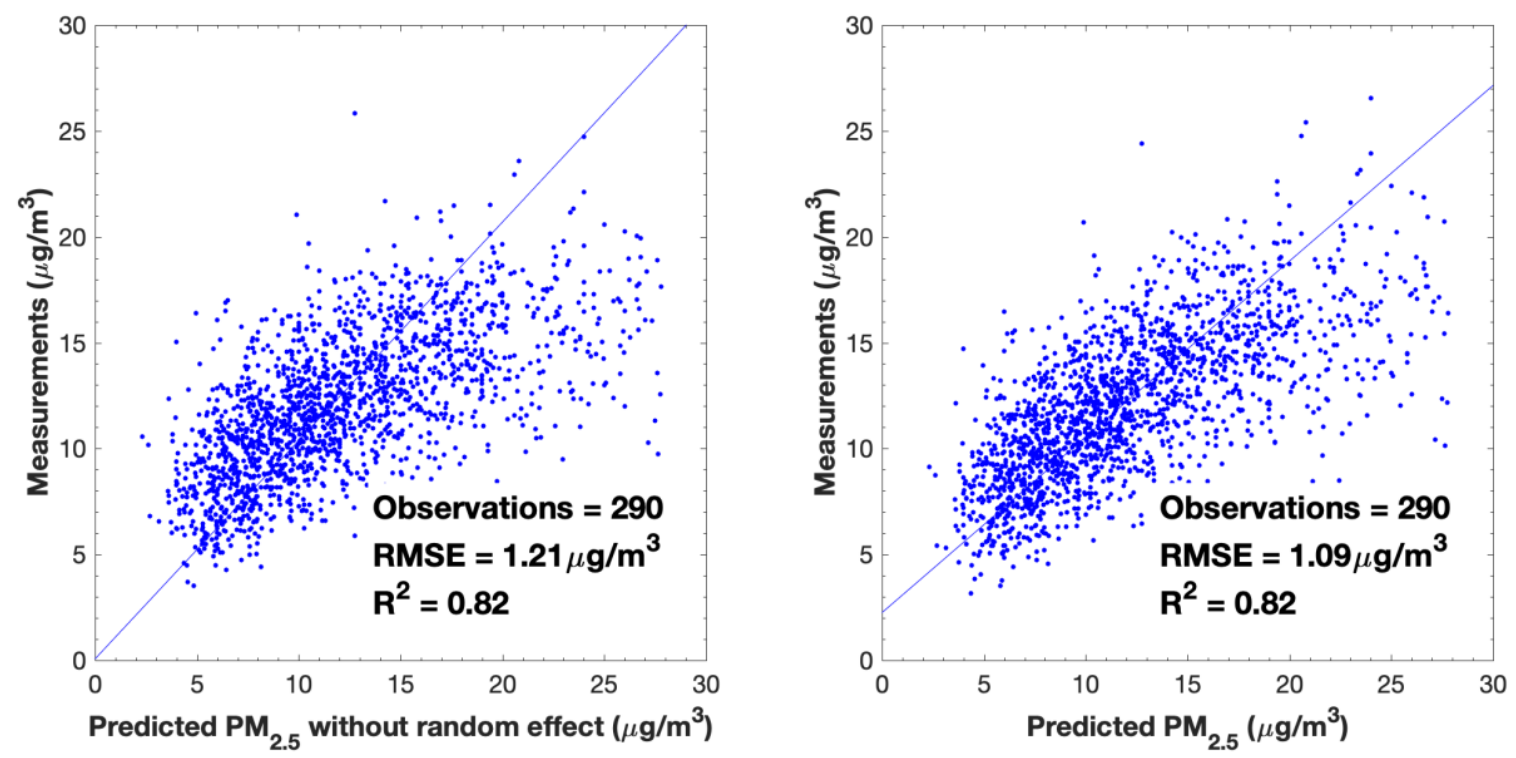

Figure S2. Predictive models of annually PM2.5 from co-located TSP measurements in Canada. The left panels are models without random effects and the right panels are models with random effects.
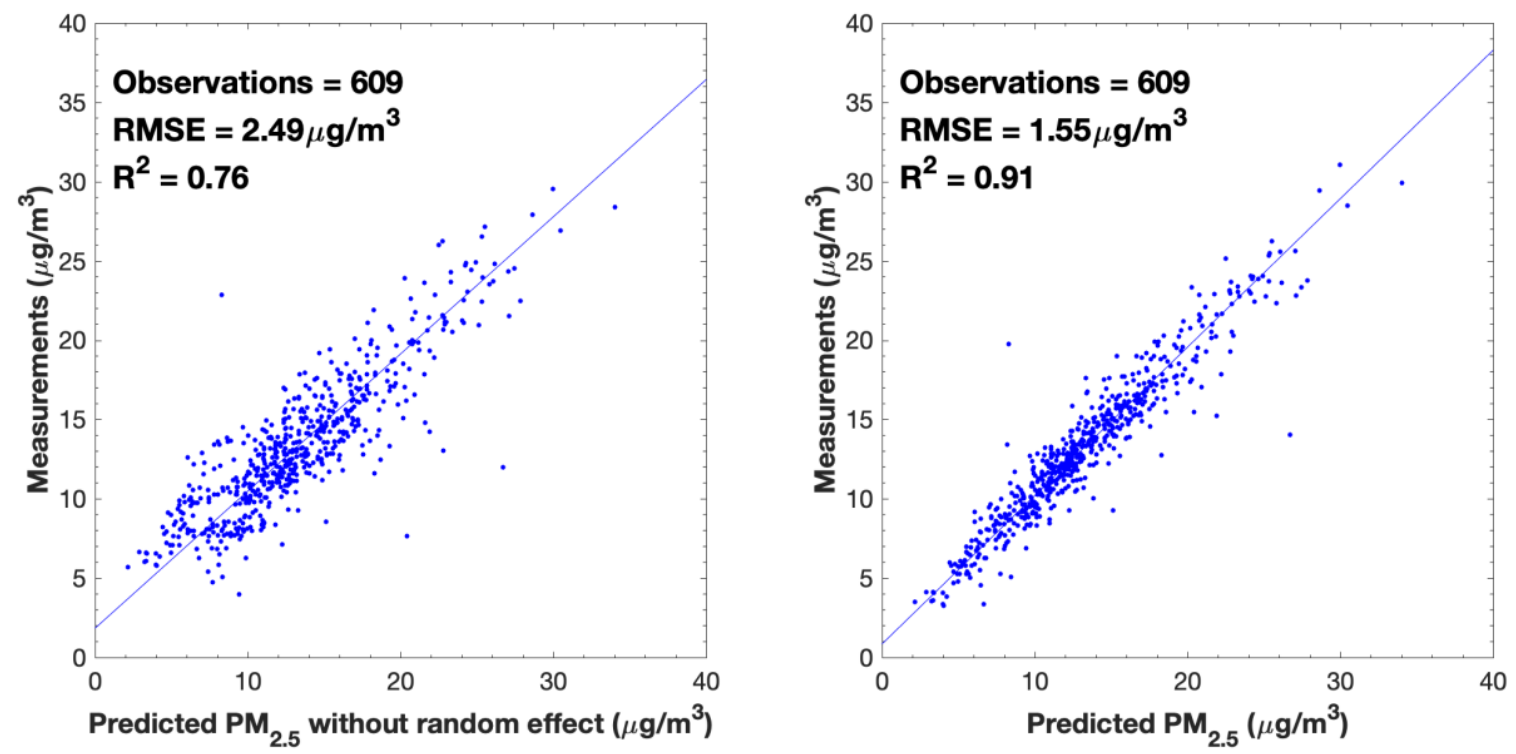

Figure S3. Predictive models of annual PM2.5 from co-located TSP measurements in the United States. The left panels are models without random effects and the right panels are models with random effects. 


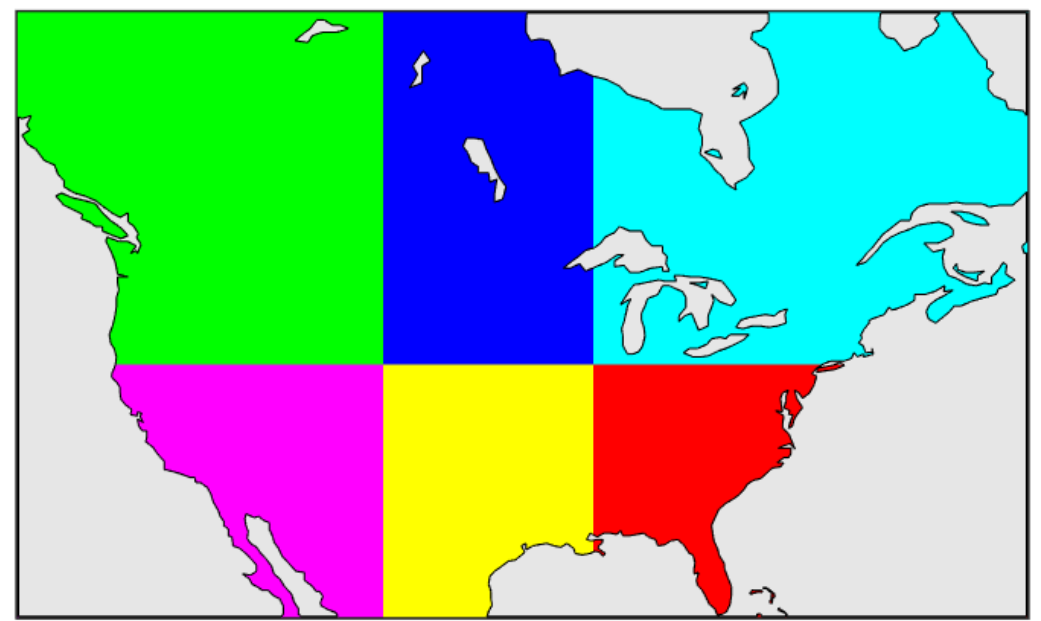

Figure S4. Domain of six regions in North America (NA), including northeastern North America (NE-NA) (Cyan), southeastern North America (SE-NA) (Red), northcentral North America (NC-NA) (Blue), southcentral North America (SC-NA) (Yellow), northwestern North America (NW-NA) (Green) and southwestern North America (SW-NA) (Magenta).

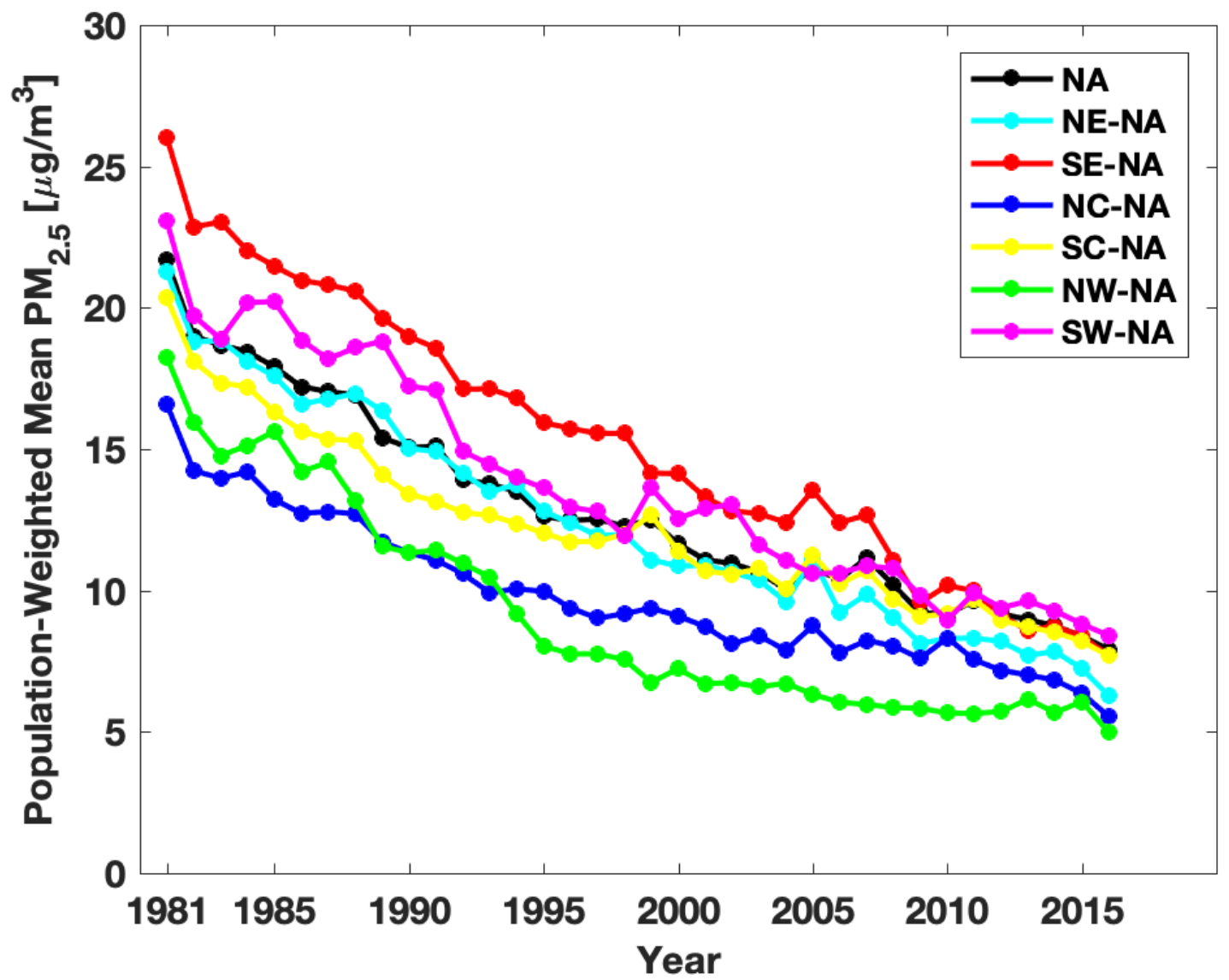

Figure S5 Population-weighted annual mean PM2.5 concentrations in different regions defined in Figure S4. 


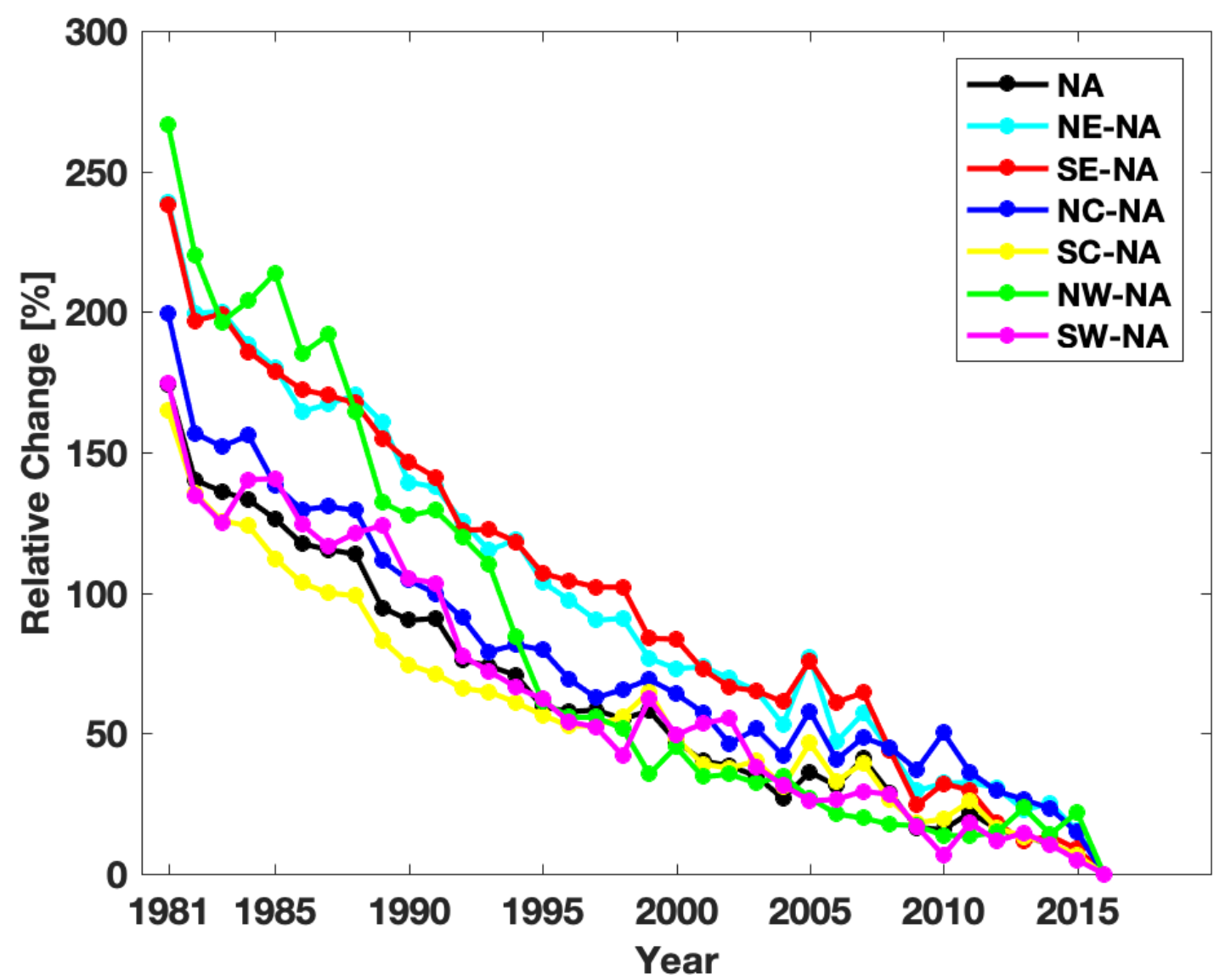

Figure S6 Relative percentage change in population-weighted PM2.5 using 2016 as the reference year. Regions are defined in Figure S4. 


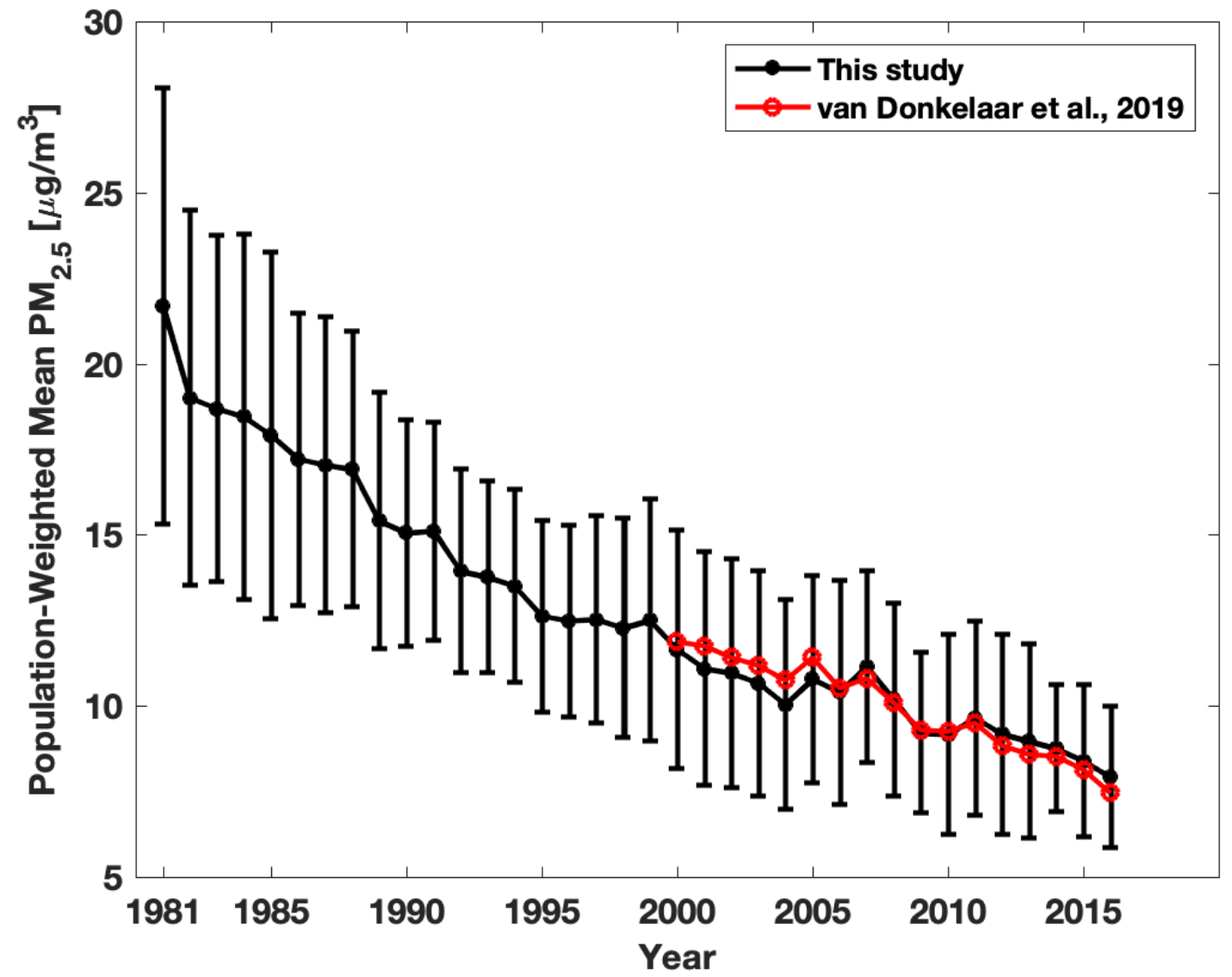

Figure S7. Time series of population-weighted average PM2.5 in this study and our most recent dataset van Donkelaar et al. ${ }^{3}$ 

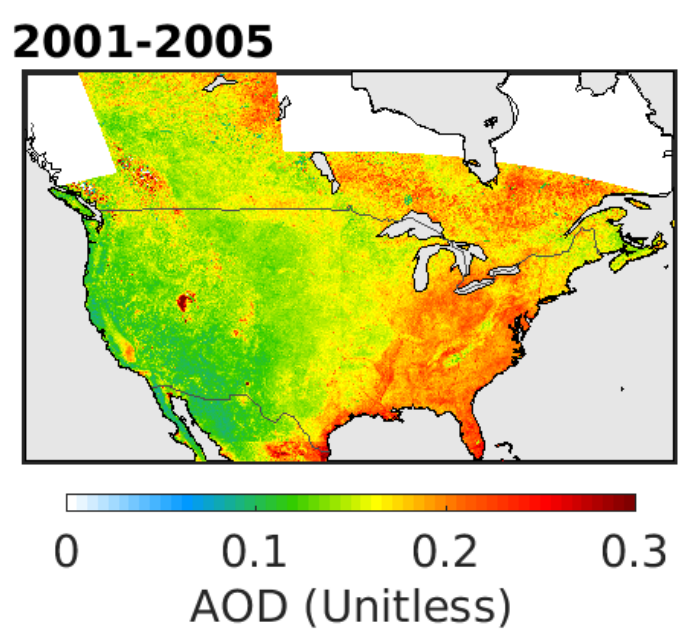

2012-2016
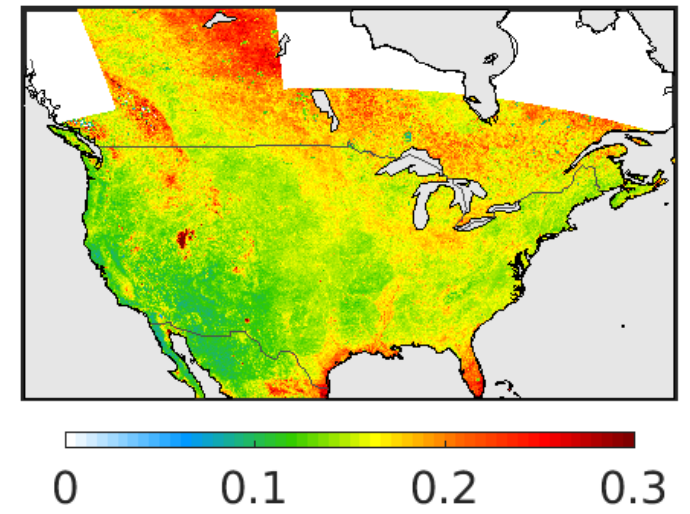

AOD (Unitless)
2004-2008
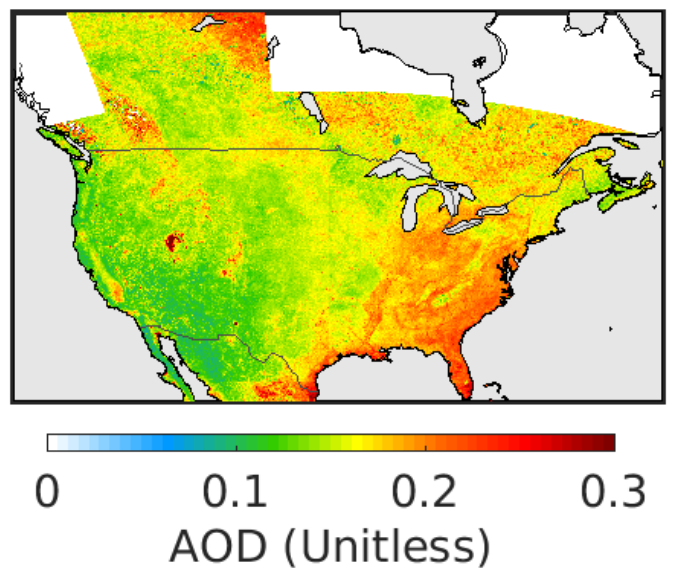

2012-2016 minus 2001-2005

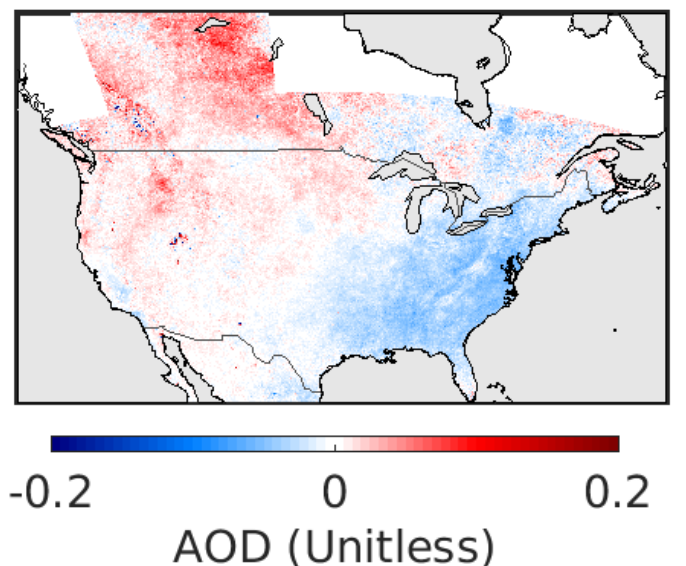

Figure S8. Aerosol optical depth (AOD) for different time periods from the MODIS MAIAC product. White indicates gaps in the availability of the regional MODIS MAIAC product. 


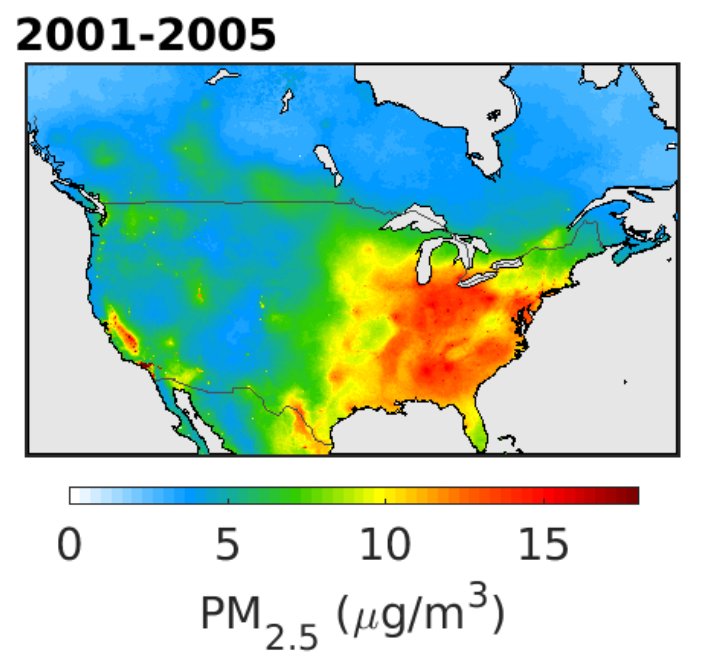

2004-2008
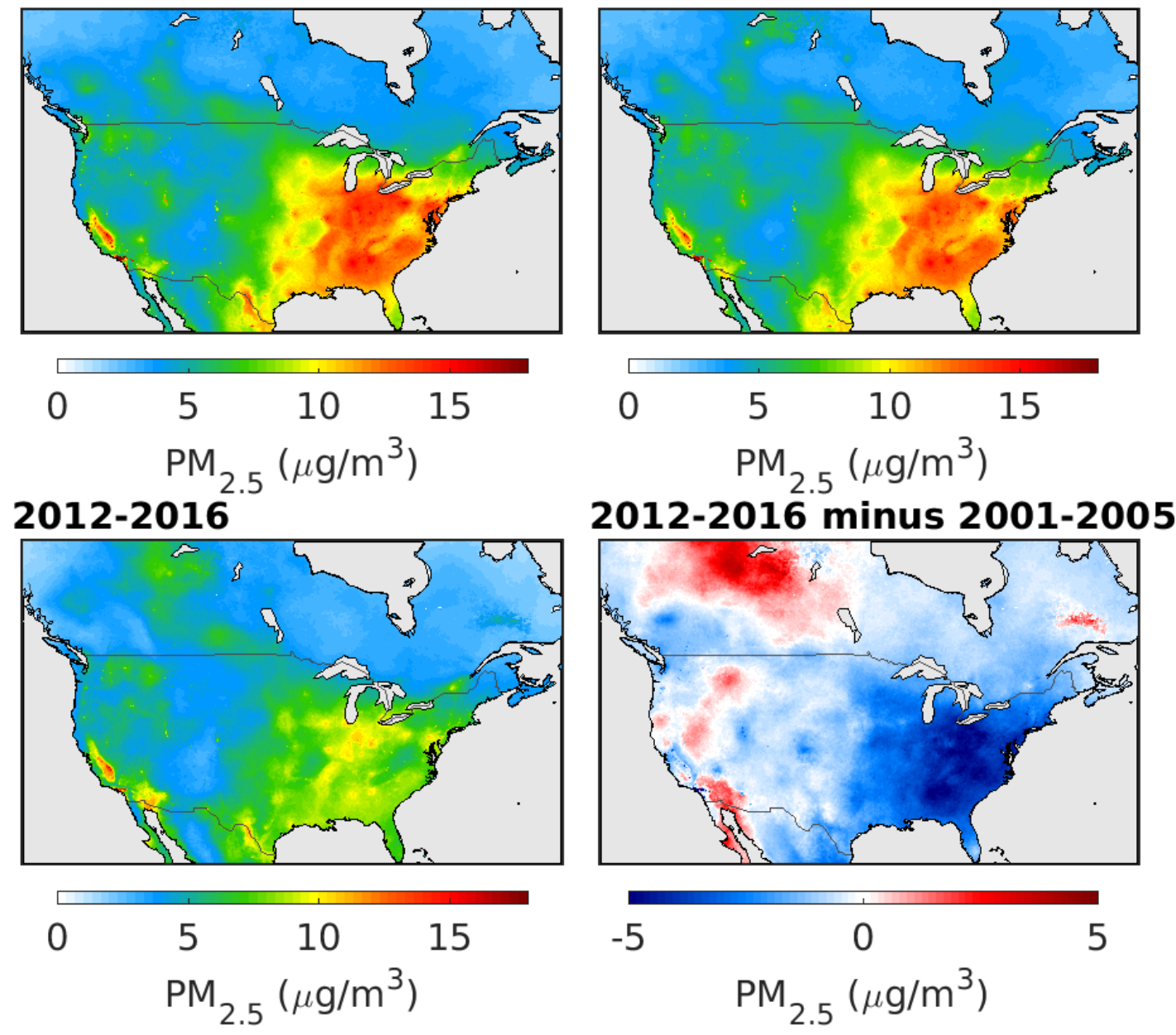

Figure S9. Spatial distribution of $P M_{2.5}$ for different time periods from van Donkelaar et al. ${ }^{3}$ 


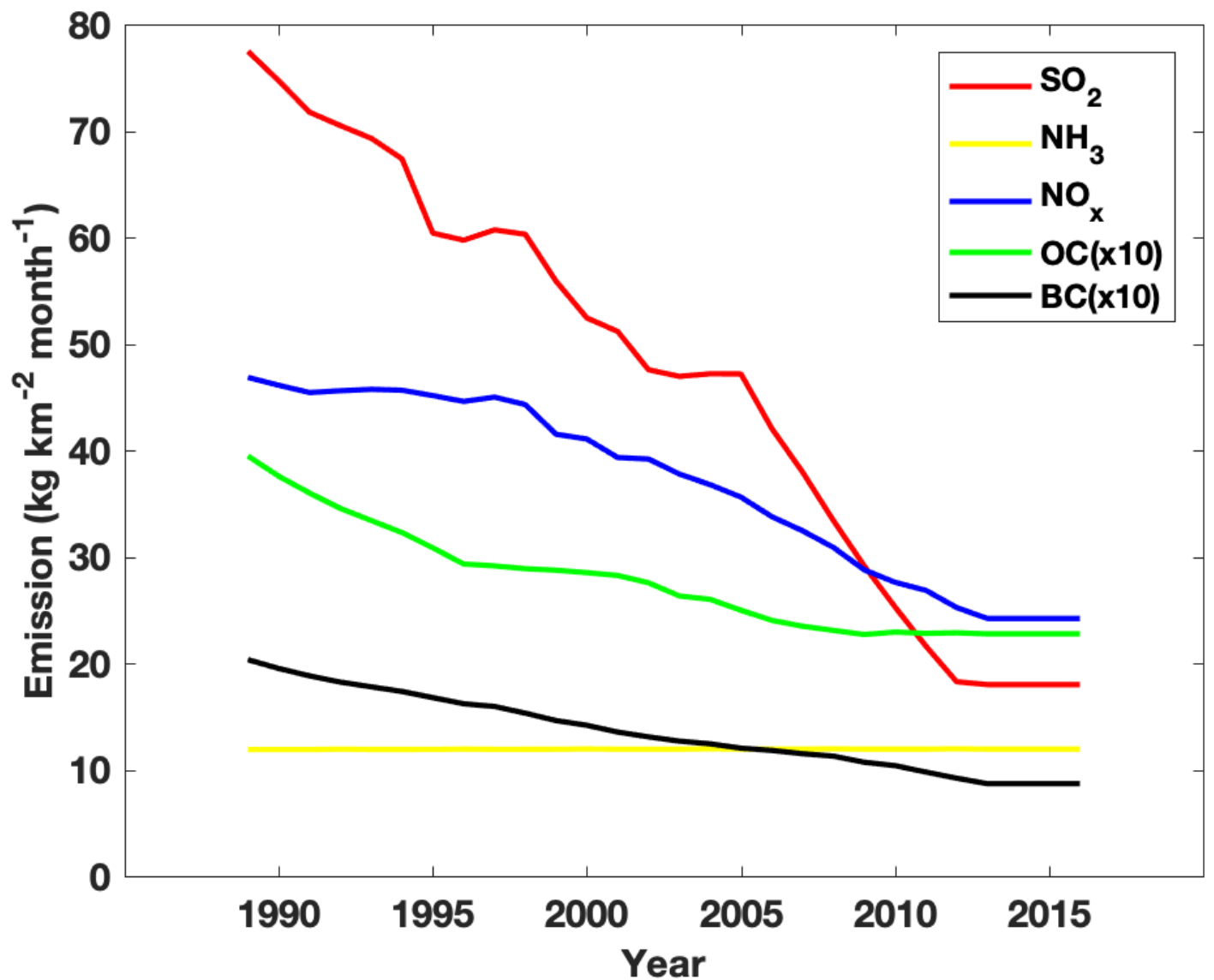

Figure S10. Time series of total anthropogenic emissions used in the simulation from 1989-2016 for $\mathrm{SO}_{2}(\mathrm{~kg} \mathrm{~S}), \mathrm{NH}_{3}(\mathrm{~kg} \mathrm{~N}), \mathrm{NOx}(\mathrm{kg} \mathrm{N}), \mathrm{OC}(\mathrm{kg} \mathrm{C})$, and $\mathrm{BC}(\mathrm{kg} \mathrm{C})$. The rates of $\mathrm{OC}$ and $B C$ emissions have been scaled by a factor of 10 in this figure to aid visualization. 


\section{References}

(1) Hinton, D.; Sune, J.; Suggs, J.; Barnard, W. F. Inhalable Particulate Network Report: Operation and Data Summary (Mass Concentrations Only). Vol. 1. April 1979-December 1982; U.S. Environmental Protection Agency, Washington, D.C., EPA/600/4-84/088A (NTIS PB85148682).

(2) van Donkelaar, A.; Martin, R. V.; Spurr, R. J. D.; Burnett, R. T. High-Resolution SatelliteDerived PM2.5 from Optimal Estimation and Geographically Weighted Regression over North America. Environ. Sci. Technol. 2015, 49 (17), 10482-10491. https://doi.org/10.1021/acs.est.5b02076.

(3) van Donkelaar, A.; Martin, R. V.; Li, C.; Burnett, R. T. Regional Estimates of Chemical Composition of Fine Particulate Matter Using a Combined Geoscience-Statistical Method with Information from Satellites, Models, and Monitors. Environ. Sci. Technol. 2019, 53 (5), 2595-2611. https://doi.org/10.1021/acs.est.8b06392.

(4) van Donkelaar A.; Martin R. V.; Brauer M.; Boys B. L. Use of Satellite Observations for Long-Term Exposure Assessment of Global Concentrations of Fine Particulate Matter. Environmental Health Perspectives 2015, 123 (2), 135-143. https://doi.org/10.1289/ehp.1408646.

(5) Lyapustin, A.; Wang, Y.; Laszlo, I.; Kahn, R.; Korkin, S.; Remer, L.; Levy, R.; Reid, J. S. Multiangle Implementation of Atmospheric Correction (MAIAC): 2. Aerosol Algorithm. Journal of Geophysical Research 2011, 116 (D3). https://doi.org/10.1029/2010JD014986.

(6) Lyapustin, A.; Martonchik, J.; Wang, Y.; Laszlo, I.; Korkin, S. Multiangle Implementation of Atmospheric Correction (MAIAC): 1. Radiative Transfer Basis and Look-up Tables. Journal of Geophysical Research 2011, 116 (D3). https://doi.org/10.1029/2010JD014985. 